\title{
Deep neck space infections in Adolescents
}

SADJ September 2021, Vol. 76 No. 8 p477- p481

S Maharaj', S Mungul ${ }^{2}$

\begin{abstract}
\section{Objectives}

Adolescent deep neck space infection is an important pathology that often requires hospitalization for antimicrobial therapy. The aim of the study was to identify the inciting organisms and their resistance profiles in the adolescent population of patients with deep neck space infection.
\end{abstract}

\section{Methods}

We performed a single-center cross-sectional retrospective analysis of patients between 10 and 16 years of age, with deep neck space infections.

\section{Results}

From the 319 cases of deep neck space infections that presented over the study period, nine patients met the criteria to be included in the study. The mean age being 11.8 years.

Themicrobiology of the specimens revealed mainly Staphylococcus and Streptococcus species and in some patients microscopy and culture showed no predominant bacteria. There was an overall $86 \%$ resistance of organisms to penicillin and ampicillin but most organisms were sensitive to amoxicillin-clavulanic acid

\section{Conclusion}

Deep neck space infections in adolescents can initially be managed with amoxicillin-clavulanic acid, source control and surgical drainage if required. Culture directed therapy can be initiated after microbiology results. The spaces involved are similar to adults with $44 \%$ of patients having deep neck abscess secondary odontogenic infection. The microbiology however is similar to that of children with Streptococcus and staphylococcus species being the most predominant.

\section{INTRODUCTION}

Adolescent deep neck space infection is an important pathology that often requires hospitalization for antimi-

\footnotetext{
Author affiliations:

1. Prof. Shivesh Maharaj: MBBCH,MMED,FCORL, Department of Neurosciences ,Yale Road, Parktown. Orcid number 00000002-2118-2400

2. Dr Sheetal Mungul: $M B B C H, B S C$, University of the Witwatersrand, Johannesburg, Gauteng, South Africa. Orcid number 0000-0003-2553-5506

Corresponding authors:

1. Prof. Shivesh Maharaj: Shivesh.maharaj@wits.ac.za

2. Dr. Sheetal Mungul: Sheetal.mungul@yahoo.com
}

crobial therapy. These infections are a distinct entity from adult and pediatric deep neck space infections as adolescence marks this transition from childhood to adulthood. Adolescence is accompanied by significant anatomical and physiologic changes. Jacqueline et al. conducted a study of immune function in adolescents and discovered a unique level of immunity in this group compared to adults and younger children. This is thought to be as a result of hormonal influences during this period of life. ${ }^{1}$

Age related anatomical differences influence the location of deep neck space infections. ${ }^{2}$ Therefore, a thorough understanding of the anatomical fascial planes which serve as a natural defense mechanism against spread, is vital for understanding the spread of disease patterns of inciting organisms seen at different anatomical sites, and treatment. ${ }^{3}$

Infections affecting deep neck spaces include lymphadenitis, cellulitis, necrotic nodes and abscesses. ${ }^{4,5}$ Ear, nose or throat infections may spread to these spaces via contiguous or lymphatic spread and may lead to abscess formation and subsequent life-threatening complications if left untreated. ${ }^{6}$

According to Lawrence, et al. in 2017, peritonsillar space infections are generally due to acute tonsillitis which often occurs paediatric patients. ${ }^{7}$ Peritonsillar abscesses are however more common in an adolescents and adults as opposed to younger children, with an average age of 25 years of patients affected. ${ }^{2}$

Submandibular space infections are usually odontogenic in origin and are therefore more prevalent in paediatrics than adults. ${ }^{6}$ However, submandibular space infections may also be due to suppurative lymphadenitis, trauma to the oral cavity and upper respiratory tract infections. ${ }^{4}$ Masticator space infections commonly arise as a result of infection from the third mandibular molar. ${ }^{4}$ Buccal infections are also commonly odontogenic in adolescents but may be non-odontogenic in younger children. ${ }^{4}$

Parotid abscesses may occur as a result of adjacent sepsis, parotitis and sialadenitis. ${ }^{2}$ These abscesses are however rare in the younger paediatric population and affected only $1 \%$ of paediatric patients in a study examining site-specific differences of deep neck space infections in children. ${ }^{6}$

Post-styloid parapharyngeal space infections are more common in children due to cervical lymphadenitis, whereas pre-styloid infections are more common in adolescents and adults due to spread from adjacent deep 
neck spaces such as submandibular, retropharyngeal, parotid and masticator spaces. ${ }^{7}$

Retropharyngeal abscesses, however, are more predominant in early childhood as opposed to adolescents as lymph nodes in these areas regress with age, and infections in this space are often due to respiratory infections, with lymph nodes in these areas draining the nose, pharynx and sinuses respectively. ${ }^{8}$ Adolescents with retropharyngeal abscesses are usually affected as a consequence of trauma or foreign body ingestion which becomes secondarily infected.

Prevertebral space infection may occur as a result of direct extension of abscesses involving the vertebra or penetrating trauma. ${ }^{4}$ Abscesses from the retropharyngeal, parapharyngeal spaces may spread to the danger space due to their proximity to this space. Infection in the anterior visceral space may arise from perforation of the anterior wall of the oesophagus due to trauma, foreign body ingestion or as a complication of surgery. ${ }^{4}$ A study by Chang et al., demonstrated that the most commonly affected anatomical sites in the head and neck region of adolescents were the peritonsillar space followed by multispace involvement whereas younger children presented with retropharyngeal or parapharyngeal spaces followed by anterior or posterior triangle and submandibular or submental regions. ${ }^{2}$

The literature is scant with regard to deep neck infections in adolescents specifically.

Rationale for study:

1. To identify the provocative organisms and their resistance profiles in the adolescent population (between 10 and 16 years of age) of patients with deep neck space infections at Charlotte Maxeke Johannesburg Academic Hospital between 1 January 2010 and 30 December 2017.

2. To describe the subtypes of deep neck space infections seen in the adolescent population and compare that with adults and children

\section{Methods}

Patients were identified by the admission books of the departments of pediatrics, maxillofacial and otorhinolaryngology.

Study criteria: Patients between 10 and 16 years of age, with deep neck space infections, who had been admitted to all wards of Charlotte Maxeke Johannesburg Academic Hospital, Gauteng, South Africa were evaluated. HIV and TB co-infection was also noted. Duration of hospitalization was used as an indicator of treatment response.

Deep neck spaces for evaluation included the submandibular, parotid, masticator, peritonsillar, parapharyngeal, retropharyngeal, pretracheal and prevertebral spaces respectively. Data was extracted from the medical records. Clinical presentation, imaging, microbiology, surgical operative reports and final outcomes were recorded and analyzed. All specimens were reassessed by a microbiologist. Management of these patients included aspiration of pus and submission to the National Health Laboratory Service for microscopy, culture and sensitivity to guide culture-directed antimicrobial therapy.

The results of these pus specimens from the National Health Laboratory Service were evaluated and the following characteristics reviewed:

- Age

- Gender

- Microbiology of infection

- Sensitivities of antimicrobials

Laboratory date available included:

- White cell count

- Haemoglobin level

- Platelets

- C-reactive protein

- Albumin level

Ethics was approved by the University of the Witwatersrand Human Research Ethics Committee (HREC)

In addition, a PubMed search, using the mesh term 'deep neck infections adolescent', was performed for literature review. The search was limited to the English language and included articles for the last 30 years until December 2019.

\section{Results}

\section{Patient Characteristics:}

From the 319 deep neck infections identified, nine patients met the criteria to be included in the study. The age range was from 10 to 15 years. The mean age being 11.8 years.

There were two females and seven males identified in the study. Two patients were HIV positive and had significantly longer average duration of hospitalization when compared to their HIV negative counterparts. One of these HIV positive patients had Tuberculosis co-infection. None of the patients in the study were anemic.

\section{Clinical signs and symptoms:}

The patients were admitted for acute neck swelling and had pyrexia, tachycardia and associated cervical lymphadenopathy. Other presenting signs and symptoms were related to the source of infection and included sore throat, trismus, otalgia, and headache. 4 patients had odontogenic infections.

The deep neck spaces of adolescents infected were the submandibular space $(n=4)$; the parotid space $(n=3)$; the buccal $(n=2)$, and peritonsillar space $(n=1)$. One patient

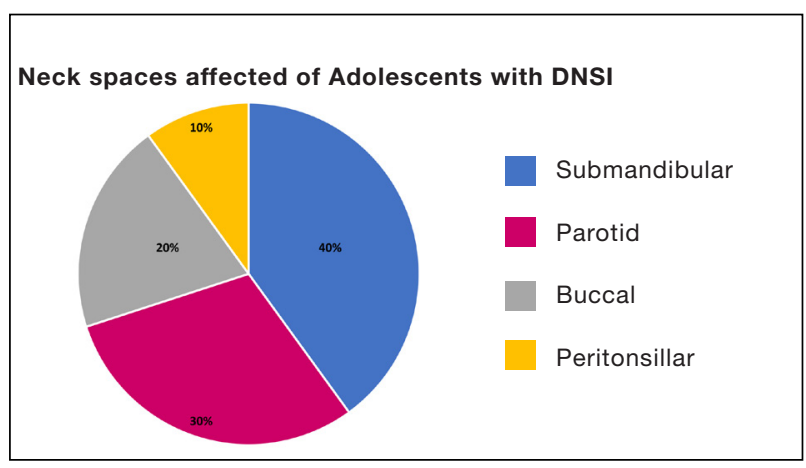

Figure 1: Neck spaces affected by DNSI in adolescent study participants 


\begin{tabular}{|c|c|c|c|}
\hline Microorganism & Percentage of patients & Sensitive to & Resistant to \\
\hline \multicolumn{4}{|l|}{ Aerobic } \\
\hline Staphylococcus aureus & 28.5 & $\begin{array}{c}\text { Cloxacillin } \\
\text { Clindamycin } \\
\text { Cotrimoxazole }\end{array}$ & $\begin{array}{l}\text { Penicillin } \\
\text { Ampicillin }\end{array}$ \\
\hline Streptococcus anginosus & 14.2 & Penicillin & Nil \\
\hline Streptococcus constellatus & 28.5 & Cefotaxime & $\begin{array}{l}\text { Penicillin } \\
\text { Ampicillin }\end{array}$ \\
\hline Proteus mirabilis & 14.2 & Amoxicillin and clavulanic acid & $\begin{array}{l}\text { Penicillin } \\
\text { Ampicillin }\end{array}$ \\
\hline \multicolumn{4}{|l|}{ Anaerobic } \\
\hline Bacteriodes fragilis & 14.2 & Amoxicillin and clavulanic acid & $\begin{array}{l}\text { Penicillin } \\
\text { Ampicillin }\end{array}$ \\
\hline
\end{tabular}

had multi-space involvement with infection of the buccal and submandibular spaces respectively. (Figure 1)

\section{Imaging}

In all patients, deep neck infection (DNI) was confirmed by radiologic investigations. Depending on the underlying pathology, availability of resources and patient characteristics, imaging consisted of ultrasonography, contrast- enhanced CT and/or MRI scan.

\section{Micro-organisms}

The microbiology of the specimens revealed: Staphylococcus aureus: Streptococcus anginosis and Streptococcus constellatus. (Table 1)

One patient with HIV had polymicrobial infection with Streptococcus constellatus, Proteus mirabilis and Bacteriodes fragilis. The other HIV infected adolescent patient had tuberculosis sensitive to isoniazid $(\mathrm{INH})$. There was an overall $86 \%$ resistance of organisms to penicillin and ampicillin. (Table 1)

\section{Blood results}

The average white cell count of patients with deep neck space infection was 9.47 (range 4.86 to 21.96), and C-reactive protein was 62 (range 11 to 259). Interestingly, patients with highest white cell counts and CRP levels on admission had the shortest duration of hospitalization. (Table 2)

\section{Treatment}

All patients were initially treated with empiric intravenous antibiotics. This was amoxicillin/clavulanic acid at the following doses:

- Patients $40 \mathrm{~kg}$ and over: Usually $1.2 \mathrm{~g} 8$ hourly.

- Patients $10-12$ years: $30 \mathrm{mg} / \mathrm{kg} 8$ hourly.

Culture directed therapy was later initiated following microbiology and sensitivities of organisms isolated. The duration of antibiotic treatment was dependent on the patient's clinical response to treatment. The days in hospital ranged from 1 to 12 days, the average being 5.8 days.

Surgery was performed for appropriate source control to drain any collections greater than $3 \mathrm{~cm}$ that was identified on imaging, This was done either intraorally for odontogenic infections with dental extractions $(n=4)$ or through an external neck incision under general anesthetic.
Five (55.6\%) pus cultures were obtained via surgical drainage, Preceding upper respiratory tract infection $n=5$ (56\%) and dental infection $n=4$ (44\%), were the leading causes of Deep neck infection.

\section{Outcomes}

All the patients improved on intravenous antibiotic treatment and surgical drainage when required.

The HIV infected patients had a much longer average duration of hospitalization of 8.5 days, indicating a delayed response to treatment. The patients were discharged and had follow-up at the out-patients clinic. The acute infection had completely resolved and there was no recurrence on follow up. Treatment for extra-pulmonary Tuberculosis was initiated for the patient with positive TB culture and was continued for a total of 9 months with complete treatment response.

\section{Discussion}

Deep neck space infection is defined as infection in the potential spaces and fascial planes of the neck. ${ }^{2}$ Ear, nose or throat infections may spread to these spaces directly or via the lymphatic system. ${ }^{4}$ Considering that we live in a developing nation burdened with HIV and other infections such as TB, compounded by the problem of malnutrition and poor access to healthcare, DNSI in our setting may have dire consequences. These complications include airway compromise, jugular vein thrombosis, carotid artery aneurysm or rupture, mediastinitis and sepsis. ${ }^{2}$ According to a study by Sittitrai et al. in 2018, HIV infected patients with deep neck space infection have a higher complication rate and a higher risk of mortality.9 Despite HIV or TB co-infection, none of the adolescents with deep neck space infection had complications during the course of disease in our study. This may reflect a protective mechanism due to hormonal influences on immunity during adolescence. ${ }^{1}$

In one study, 113 pediatric patients were hospitalized with maxillofacial infections with 32 from dental sources; however, the extension of these infections into deep neck spaces was not documented. In a similar study of 67 paediatric patients with abscess of the head and neck, only 15 cases were determined to have submandibular, parapharyngeal, or retropharyngeal space involvement, and only nine were attributed to dental infection. ${ }^{4,5,10-13}$ In our study the submandibular space was the most affected across all adolescents. Submandibular space infections are usually odontogenic in origin and are less 


\begin{tabular}{|c|c|c|c|c|c|c|c|}
\hline Patient No. & Gender & Age & $\begin{array}{l}\text { White cell } \\
\text { count }\end{array}$ & $\mathrm{Hb}$ & Platelets & CRP & HIV result \\
\hline 1. & Male & 10 & 6.74 & 11.9 & 475 & 45 & - \\
\hline 2. & Female & 10 & 4.86 & 13.51 & 278 & 22 & + \\
\hline 3. & Male & 11 & 10.2 & 14 & 237 & 117 & - \\
\hline 4. & Male & 11 & 6.5 & 11.9 & 612 & 47 & - \\
\hline 5. & Male & 10 & 7 & 13.1 & 413 & 35 & - \\
\hline 6. & Male & 13 & 5.0 & 11.8 & 345 & 11 & + \\
\hline 7. & Male & 14 & 11.6 & 12.1 & 389 & 13 & - \\
\hline 8. & Male & 15 & 21.96 & 12.9 & 258 & 259 & - \\
\hline 9. & Female & 13 & 11.4 & 12.4 & 320 & 15 & - \\
\hline
\end{tabular}

prevalent in babies or younger children than adolescents. This is in keeping with international trends. ${ }^{6-8}$

It is also evident that although retropharyngeal abscesses are commonly seen in some countries in the younger pediatric population, it is relatively rare in the adolescent population due to the regression of lymph nodes, and none of the patients presented with retropharyngeal abscesses during our study period. ${ }^{8}$

The incidence of peritonsillar abscess was low in our study due to our inclusion criteria of patients with microbiology results only. It was however noted that an older adolescent patient was affected which is consistent with the literature. ${ }^{2}$ At our institution, most patients with peritonsillar abscesses are treated medically, and it is not routine to send off aspirates for microbiology in uncomplicated cases. It is therefore estimated that the true incidence of peritonsillar abscess in the adolescent population is probably much higher.

Parotid space abscess affected $1 \%$ of pediatric patients ${ }^{8}$. However, in our study, 33\% of adolescents presented with a parotid space abscess, one as a result of tuberculosis infection.

Microbiological studies of patients with deep neck space infections demonstrated that the main inciting organisms are bacterial in origin, but these bacteria may differ in pediatrics to those seen in the adult population. ${ }^{7}$ This may be because adult deep neck space infections are generally due to dental pathology whereas pediatric deep neck space infections may be due to a spectrum of disease such as tonsillitis, pharyngitis, hematogenous spread and suppurative cervical lymphadenitis. ${ }^{14,15}$ The microbiology of deep space neck infections continues to evolve. In 1983, Streptococci (61\%) and Staphylococcus species $(32 \%)$ comprised the majority of pure cultures in neck space infections, predominantly secondary to dental pathology ${ }^{6}$. Brook found that the most common isolates in peadiatric head and neck infections are Staphylococcus aureus (aerobic) and Bacteroides species. ${ }^{5}$ Other studies report that most common pathogens isolated in deep neck space infections include aerobes such as group A Streptococcus and Staphylococcus aureus. ${ }^{9}$

The results of our study are consistent with the literature, with Streptocccal and Staphylocci species being the most common isolates in the adolescent age-group. Adolescents in the school-age group are often candidates for Streptococcus pyogenes throat infections that may result in these patients being more prone to peritonsillar abscesses. However, no Streptococcus pyogenes was identified in the peritonsillar abscess in our study.

Deep neck space infections are most often polymicrobial in adults, and these organisms reflect the microbial spectrum found in the oral cavity. The pathogens commonly isolated from pus cultures are group A Streptococcus, oropharyngeal anaerobic bacteria, and S. aureus. ${ }^{1,3,8}$ Other pathogens may include Haemophilus influenzae and Klebsiella pneumoniae in diabetic patients. ${ }^{16}$

Preceding upper respiratory tract infection (56\%) and dental infection (44\%), were the leading causes of DNI in our study. This indicates that adolescent patients may present with a spectrum of pathology seen in both children and adults.

Limitations of this study include the fact that it is a retrospective analysis, small sample size due to the relatively low prevalence of this infection in the adolescent age group, and single-medical center data. Empirical antimicrobial coverage may have affected the microbiologic findings in those specimens which were culture negative. However, the characteristics of deep neck space infections in adolescent patients can still be identified from this study. The main causative pathogens from cultures, antimicrobial sensitivity and resistance patterns have also been identified.

\section{Conclusion}

Deep neck space infections in adolescent patients should be diagnosed early and can often be successfully managed with medical therapy and surgical intervention when necessary. The spaces involved are similar to adults with $44 \%$ of patients having deep neck abscess secondary odontogenic infection. The microbiology however is similar to that of children with Streptococcus and staphylococcus species being the most predominant. The complication rate of $\mathrm{DNI}$ in adolescents is low.

\section{Acknowledgements: None}

The study was funded by the authors

The is no conflict of interest

\section{References}

1. Bartlett JA, Schleifer SJ, Demetrikopoulos MK, et al. Immune function in healthy adolescents. Clin Diagn Lab Immunol 1998; 5:105-113.

2. Chang L, Chi H, Chiu NC, et al. Deep neck infections in different age groups of children. J Microbiol Immunol Infect 2010; 43:47- 52 
3. Johnson JT, Rosen CA. Bailey's Head and Neck Surgery: Otolaryngology, 5th ed. Lippincott Williams \& Wilkins, 2013, pp. 794 - 811.

4. Dodson TB, Perrott DH, and Kaban LB. Paediatric maxillofacial infections: a retrospective study of 113 patients. J Oral Maxillofac Surg 1989; 47:327-30.

5. Brook I. Microbiology of abscesses of the head and neck in children. Ann Otol Rhinol Laryngol 1987; 196:429-33.

6. Megran DW, Scheifele DW and Chow AW. Odontogenic infections. Pediatr Infect Dis 1984; 3:257-65.

7. Lawrence $\mathrm{R}$ and Bateman N. Controversies in the management of deep neck space infection in children: an evidence-based review. Clin Otolaryngol 2017; 42:156-63.

8. Vieira F, Allen S, and Stocks RMS. Deep neck infection. Otolaryngol Clin North Am 2008; 41:459-83.

9. Sittitrai P, Srivanitchapoom C, Reunmakkaew D . Deep neck infection in patients with and without human immunodeficiency virus: a comparison of clinical features, complications, and outcomes. $\mathrm{Br} J$ Oral Maxfac Surg 2018; 56 : 962-67

10. Songu M, DeMiray U, Adibelli ZH, et al. Bilateral deep neck space infection in the paediatric age group: a case report and review of the literature. Acta Otorhinolaryngol Ital 2011; 31:190-93.

11. Pappas DE and Hendley JO. Retropharyngeal abscess, lateral pharyngeal (parapharyngeal) abscess, and peritonsillar cellulitis/abscess. In: Kliegman RM,
Behrman RE, Jenson HB, Stanton BF (eds). Nelson textbook of pediatrics. 19th ed. Philadelphia: Saunders, 2011, pp.1440-42.

12. Naidu SI, Donepudi SK, Stocks RM, et al. Methicillinresistant Staphylococcus aureus as a pathogen in deep neck abscesses: a pediatric case series. Int J Pediatr Otorhinolaryngol 2005; 69:1367-71.

13. Liu CH, Lin CD, Cheng YK, et al. Deep neck infection in children. Acta Paediatr Taiwan 2004; 45:265-68.

14. Grisaru-Soen G, Komisar $O$, Aizenstein $O$, et al. Retropharyngeal and parapharyngeal abscess in children epidemiology, clinical features and treatment. Int J Pediatr Otorhinolaryngol 2010; 74:1016-20.

15. Ungkanont K, Yellon RF, Weissman JL, et al. Head and neck space infections in infants and children. Otolaryngol Head Neck Surg 1995; 112:375-82.

16. Lee $Y Q$ and Kanagalingam J. Deep neck abscesses: The Singapore experience. Eur Arch Otorhinolaryngol 2011; 268:609-14.

\section{Do the CPD questionnaire on page 501}

The Continuous Professional Development (CPD) section provides for twenty general questions and five ethics questions. The section provides members with a valuable source of CPD points whilst also achieving the objective of CPD, to assure continuing education. The importance of continuing professional development should not be underestimated, it is a career-long obligation for practicing professionals.

\section{Online CPD in 6 Easy Steps}

Go to the SADA website www.sada.co.za

2 Log into the 'member only' section with your unique SADA username and password.

3 Select the CPD navigation tab.

4 Select the questionnaire that you wish to complete.

5 Enter your multiple choice answers. Please note that you have two attempts to obtain at least $70 \%$

$6 \quad$ View and print your CPD certificate. 